\title{
Assessment of wound dressing practices among nurses at the emergency hospitals in Erbil city
}

Abstract

Background and objective: Wound dressing is one of the major nursing responsibilities Aseptic technique is mandatory to minimize complications. Effective wound dressing promotes wound healing and leads to early discharge and saving costs. This study aimed to assess wound dressing practices among nurses in Erbil emergency hospitals and determine the relationship between the practices and the sociodemographic characteristics.

Methods: A descriptive study was conducted at three Emergency Hospitals in Erbil city. This study was carried out from November $17^{\text {th }}, 2014$ to November $17^{\text {th }}, 2015$ on a non-probability purposive sample of 64 nurses who worked at emergency reception department of three emergency hospitals. The questionnaire was constructed for data collection which consisted of two parts; part I of the questionnaire included demographical characteristics of nurses and part II contained an observational checklist that consists of 24 items of nurses' wound dressing practice. Data were collected through the direct observant approach and analyzed through the application of descriptive analysis measures (frequencies and percentages) and inferential statistical analysis (chi-square and Fisher's exact test).

Results: Majority (65.6\%) of nurses' wound dressing practices were at the medium level of practice and minority (34.4\%) were at high level. The highest steps practiced was with irrigation and dressing items (1.61), and lowest with the discard wound dressing supplies items (0.79). There was no significant association between the wound dressing practice and nurses' chararacteristics of age, gender, educational level, years of experience and training participation ( $P=0.51,0.609,0.54,0.21$ and 0.78 , respectively).

Conclusion: The overall nurses' wound dressing practice was suboptimal and not impressive and the worse practice with items related to wound dressing infection control practice.

Keywords: Assessment; Wound dressing; Emergency Hospital.

\section{Introduction}

A wound defined as a defect or break in the skin that results from physical, mechanical or thermal damage, or that develops as a result of the presence of an underlying medical or physiological disorder. ${ }^{1}$ Today wound infection increased the financial cost on the patients and the hospitals in respect to the increase in hospitalization, increase the use of antibiotics, increase in the consumption of medical supplies, increase of time consuming for personnel in the health sector. ${ }^{2}$ The dressing protects the wound from injury, prevents introduction of bacteria, reduces discomfort, and speeds healing. The dry dressing does not debride the wound; hence, it is not for wounds requiring debridement. In addition, a dry dressing is not appropriate for an open wound that is healing by secondary intention. If a dry dressing adheres to a wound, the dressing should be moistened with sterile normal saline or sterile water before the woven dressing is removed.

* Erbil Director of Health, Erbil, Iraq.

** Department of Nursing, College of Nursing, Hawler Medical University, Erbil, Iraq. 
Moistening the dressing in this manner decreases the adherence of the dressing to the wound and reduces the risk for further trauma to the wound. ${ }^{3}$ The standard of care for wound cleaning and irrigation of acute wounds in reducing the risk of infection and promoting optimum healing has been the subject of evolving research over the past several decades. Wound cleansing and irrigation for acute lacerations is one of the most frequent procedures performed to remove loose devitalized tissue, bacteria, and foreign bodies. ${ }^{4}$ Prevention of infection is the best response and there is several first aid responses can do to accomplish this. Clean the wound and apply an antiseptic over it immediately protect the open wound against bacterial invasion by covering it with a clean bandage or gauze. ${ }^{5}$ Each year millions of patients with acute lacerations present to emergency departments for treatment. According to the director of health in Erbil (2014) about 55373 injured patients were treated in Erbil emergency hospitals during 2013 . Limited studies in Iraq, ${ }^{2,6}$ but no studies in Kurdistan region have been done to assess wound dressing. Wound dressing care is an essential part of treatment. The researchers realized the importance of this practice to assess the wound dressing practice in our hospitals hoping to identify how to practice this procedure and so to start a simple attempt guide them to standard practices as possible. This study aimed to assess nurses practices regarding wound dressing, describe the demographic characteristics of the nurses who worked in emergency reception such as (age, gender, level of education, year of experience participation in training on wound dressing) and find out the relationship between nurses practices and their demographic characteristics.

\section{Methods}

A quantitative study was designed to assess the wound dressing practice among a non-probability purposive sample of 64 nurses who worked in reception department of East Emergency and West Emergency Hospitals, Emergency management center in Erbil City. This study was carried out from the period of Nov. $17^{\text {th }}, 2014$ to Nov. $17^{\text {th }}, 2015$. Formal administrative approval was obtained from the General Directorate of Health /Erbil for carrying out this study in the emergency hospitals in Erbil city. Ethical approval was obtained from the Ethics Committee at the College of Nursing/ Hawler Medical University. Data were collected using observation checklist during the period of $2^{\text {nd }}$ February 2015 to $17^{\text {th }}$ May 2015. Nurses' were observed by the researcher while they worked, each of them was observed on individual base without being informed and the time allocated for each dressing was 10-20 minutes. Inclusion criteria of the study sample were: both male and female nurse who had more than one year of experience in acute wound dressing practice at emergency reception department. The exclusion criteria included nurses who are not available at the time of data collection and all wounds except burn wound. The questionnaire consisted of two parts. Part I: Demographic characteristics included 7 variables (age, gender, levels of education, duration of experience in wound dressing, participation in training session wound dressing and hospitals setting). Part II: included observational checklist a questionnaire was constructed and modified by the researchers which consist of 24 items based on Louis Mosby skills checklist for wound dressing. ${ }^{7-10}$ The observational checklist was rated three point Likert scale as always, sometimes and never and it was scored as (2) for always, (1) for sometimes, and (0) for never. The overall wound dressing practice (24 items) scored from 0 to 48 scores. Wound dressing practice scores were categorized into three levels like low practice (0-16), Medium practice (16.1-32), and high practice (32.1-48). The higher scores of mean the best nurses' wound dressing practices. Wound dressing 
practice checklist of 24 items included three sub stages; the first seven items about preparation and assessment, the middle 14 items about irrigation and dressing practice and the final three items about discarded wound dressing supplies. Grand mean score that calculated by summation of all mean score / number of items. Overall wound dressing practices were classified to more than medium score and less than medium. Grand mean score of overall wound dressing practices was at the medium score of practice and $=1.32$ When: Median score of preparation items = 1.13 for wound irrigation and dressing = 1.63 and Median score of wound dressing supplies $=1.52$. Data were analyzed using the statistical package for the social sciences for Windows (version 20). It includes descriptive statistical analysis (frequency, percentage) and inferential statistical analysis (Chi-square and Fisher's exact test).

\section{Results}

Table 1 shows that the highest percentage of nurses $(48.4 \%)$ were had less than 30 years old; $60.9 \%$ of them were males, most of them $(82.8 \%)$ were having diploma in nursing, with $(62.5 \%)$ of the nurses within less than five years of experience and about $68.8 \%$ of them did not participate in training regarding wound dressing practice majority of nurses (68.8\%) were from Rozhawa Emergency Hospital.

Table 1: Demographic characteristics of the nurses.

\begin{tabular}{|c|c|c|c|}
\hline Variables & & No. & $\begin{array}{c}\% \\
\mathrm{n}=64 \\
\end{array}$ \\
\hline \multirow[t]{4}{*}{ Age group (years) } & $<30$ & 31 & 48.4 \\
\hline & $30-34$ & 15 & 23.4 \\
\hline & $35-39$ & 10 & 15.6 \\
\hline & $\geq 40$ & 8 & 12.5 \\
\hline \multirow[t]{2}{*}{ Gender } & Male & 39 & 60.9 \\
\hline & Female & 25 & 39.1 \\
\hline \multirow[t]{3}{*}{ Educational level } & Nursing high school & 7 & 10.9 \\
\hline & Diploma in nursing & 53 & 82.8 \\
\hline & B.Sc. in nursing & 4 & 6.2 .0 \\
\hline \multirow[t]{3}{*}{ Years of experience } & $<5$ & 40 & 62.5 \\
\hline & $5-9$ & 17 & 26.6 \\
\hline & $\geq 10$ & 7 & 10.9 \\
\hline \multirow{2}{*}{$\begin{array}{l}\text { Participate in training regarding } \\
\text { wound dressing }\end{array}$} & Yes & 20 & 31.2 \\
\hline & No & 44 & 68.8 \\
\hline \multirow[t]{3}{*}{ Hospital Setting } & $\begin{array}{l}\text { Emergency Management } \\
\text { Center }\end{array}$ & 12 & 18.8 \\
\hline & $\begin{array}{l}\text { Rozhhalat(East) Emergency } \\
\text { Hospital }\end{array}$ & 8 & 12.4 \\
\hline & $\begin{array}{l}\text { Rozhawa(West) Emergency } \\
\text { Hospital }\end{array}$ & 44 & 68.8 \\
\hline
\end{tabular}


Table 2 shows that the grand mean score of overall wound dressing practice was at the level of medium scores of nursing practice. From the total 24 items 8 items of them $(1,2,3,4,8,14,23,24)$ were with low mean scores $(0.38,0.0,0.0,1.22$, $0.88,0.23,0.0,0.38$ respectively) within low wound dressing practice most of those items related to infection control practice.

Table 2: Mean score of overall wound dressing practice.

\begin{tabular}{|c|c|c|}
\hline No. & Wound dressing practice items & MS \\
\hline $1^{*}$ & Preparation of sterile field with equipment & 0.38 \\
\hline $2^{*}$ & Performed hand washing & 0 \\
\hline $3^{*}$ & Wearing sterile gloves. & 0 \\
\hline 4 & Closed room door or pulled curtain around the bed (privacy). & 1.22 \\
\hline 5 & Positioned patient comfortably & 1.94 \\
\hline 6 & Assessed for adjacent bony injury or open fractures & 1.88 \\
\hline 7 & Assessed tetanus immunization status and (bite wounds) & 1.55 \\
\hline 8 & Anesthetized the area. & 0.88 \\
\hline 9 & Draped or undressed the patient if irrigation were planned & 1.8 \\
\hline 10 & Maintained hemostasis by applying gauze over the wound & 1.41 \\
\hline 11 & Shaving & 1.5 \\
\hline 12 & Irrigated the wound by using normal saline & 1.86 \\
\hline 13 & scrub the skin around the wound with the antiseptic agent & 1.97 \\
\hline $14^{*}$ & Started skin scrub at the edge of the wound and moved distally & 0.23 \\
\hline 15 & Consulted the practitioner and obtained radiographic imaging as requested & 1.66 \\
\hline 16 & Covered the wound with a sterile dressing pending wound closure & 1.38 \\
\hline 17 & Wound suturing & 1.96 \\
\hline 18 & Sterilizing wound area with antiseptic & 2 \\
\hline 19 & Applied loose dressing as a primary contact layer & 2 \\
\hline 20 & Applied additional layers of dressing, thicker pad as needed & 1.88 \\
\hline 21 & Secured dressing with bandage, tape & 2 \\
\hline 22 & Discarded supplies. & 2 \\
\hline $23^{*}$ & Performed hand hygiene & 0 \\
\hline 24 & Documented the procedure in the patient's record & 0.38 \\
\hline
\end{tabular}


Figure1 show that the lower grand mean scores of wound dressing practice were with discard wound dressing supply 0.79 items and preparation and assessment items 0.99. Wound irrigation and dressing items had higher grand mean score than overall wound dressing practice with grand mean scores (1.61 and 1.32 respectively). Table 3 shows that there was no significant association between wound dressing practice and nurses 'demographic characteristics like age, gender, educational level, years of experience and training participation with $P=0.51$, $0.609,0.54,0.21$ and 0.78 , respectively. There was a significant association between the wound dressing practice and hospital setting of nurses with $P=0.005$. All nurses in emergency management center were had above median score on wound dressing practice.

Table 3: Associations between wound dressing practice and nurses' demographic characteristics

\begin{tabular}{|c|c|c|c|c|c|c|c|}
\hline \multirow{3}{*}{$\begin{array}{l}\text { Demographic characteristics of } \\
\text { nurses }\end{array}$} & \multicolumn{6}{|c|}{ Mean score of wound dressing practice } & \multirow{3}{*}{$\begin{array}{l}P \text { value } \\
\text { Chi-square }\end{array}$} \\
\hline & \multicolumn{2}{|c|}{$\leq$ Median } & \multicolumn{2}{|c|}{$>$ Median } & \multicolumn{2}{|c|}{ Total } & \\
\hline & $\mathbf{F}$ & $\%$ & $\mathbf{F}$ & $\%$ & $\mathbf{F}$ & $\%$ & \\
\hline \multicolumn{8}{|l|}{ Age (years) } \\
\hline$<30$ & 14 & 45.2 & 17 & 54.8 & 31 & 100 & \multirow{4}{*}{0.51} \\
\hline $30-34$ & 7 & 46.7 & 8 & 53.3 & 15 & 100 & \\
\hline $35-39$ & 2 & 20 & 8 & 80 & 10 & 100 & \\
\hline$\geq 40$ & 3 & 37.5 & 5 & 62.5 & 8 & 100 & \\
\hline \multicolumn{8}{|l|}{ Gender } \\
\hline Male & 17 & 43.6 & 22 & 56.4 & 39 & 100 & \multirow{3}{*}{0.609} \\
\hline Female & 9 & 36 & 16 & 64 & 25 & 100 & \\
\hline Total & 26 & 40.6 & 38 & 59.4 & 64 & 100 & \\
\hline \multicolumn{8}{|l|}{ Level of education } \\
\hline Nursing high school & 4 & 57.1 & 3 & 42.9 & 7 & 100 & \multirow{3}{*}{$0.54^{*}$} \\
\hline Diploma in nursing & 21 & 39.6 & 32 & 60.4 & 53 & 100 & \\
\hline B.Sc. & 1 & 25 & 3 & 75 & 4 & 100 & \\
\hline \multicolumn{8}{|l|}{ Years of experience } \\
\hline$<5$ & 16 & 40 & 24 & 60 & 40 & 100 & \multirow{3}{*}{0.21} \\
\hline $5-9$ & 9 & 52.9 & 8 & 47.1 & 17 & 100 & \\
\hline$\geq 10$ & 1 & 14.3 & 6 & 85.7 & 7 & 100 & \\
\hline \multicolumn{8}{|l|}{ Training participation } \\
\hline Yes & 9 & 45 & 11 & 55 & 20 & 100 & \multirow[b]{2}{*}{0.78} \\
\hline No & 17 & 36,6 & 27 & 61.4 & 44 & 100 & \\
\hline \multicolumn{8}{|l|}{ Hospital setting } \\
\hline Emergency management center & 0 & 0.0 & 12 & 100 & 0 & 100 & \multirow{4}{*}{0.005} \\
\hline Emergency Hospital Rojhallat & 5 & 62.5 & 3 & 37.5 & 8 & 100 & \\
\hline Emergency Hospital Rojawa & 21 & 47.7 & 23 & 52.3 & 44 & 100 & \\
\hline Total & 26 & 40.6 & 38 & 59.4 & 64 & 100 & \\
\hline
\end{tabular}

* By Fisher's Exact Test

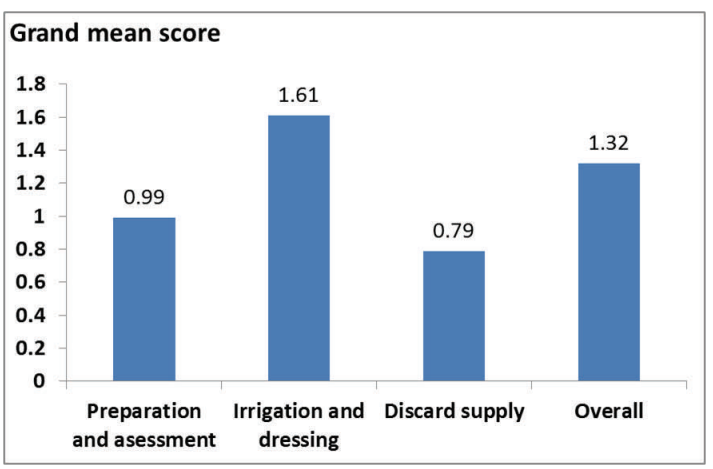

Figure 1: Mean scores of wound dressing practice steps with overall practice. 
Table 4 shows the overall nurses wound dressing practice. The higher percentage $65.6 \%$ of nurses have had a medium score of wound dressing practice; while the lower percentage $34.4 \%$ of them with high score of wound dressing practice.

\section{Discussion}

In this study the result shows that majority of nurses were within $\leq 35$ years of age, having a diploma in nursing. Most of the nurses were from the West Emergency Hospital; this is due to the fact that the West Emergency Hospital is more crowded during all three shifts and having different units for each female and male patients, while the other emergency hospitals had one unit for both. A high percentage of the nurses was males with $<5$ years of experience and majority of them did not train on the wound dressing. The majority of the study sample was with age group less than 35 years old; this result is supported by the study of ${ }^{2}$ in Baghdad city they found that most of the study sample was less than 35 years old. Regarding the nurse's gender most of the nurses were males this may be related to male nurses more interested working in emergency hospitals and less engaged in home duties than females especially during night shifts thus the policy of emergency hospitals provide male nurses more than females. This result is in contrast to a study from Benghazi, Libya, which indicated that the majority of the study samples were female. ${ }^{11}$ Concerning the level of education, majority of study sample having diploma in nursing this may be related to the establishment of the College of Nursing from the last decade in Kurdistan region while medical institute more longer time.
This result supported by results of studies from Bangladesh ${ }^{12}$ and $^{1}$ Mulago $^{3}$ that indicated that the majority of sample study had diploma in nursing. Regarding the years of experience, most of the study sample was had less than five years of experience, this result was agreed by another study, ${ }^{14}$ which found that most of the nurses had an experience of less than five years. Regarding training on the wound dressing the results show that the majority of the study sample was not trained on wound dressing practice, this may be related to the policy of the hospitals and ministry of health were negligent to improve quality of nurse's skills on wound dressing practice. This result was supported by the results of Atiyah et al. on 55 nurses in Baghdad, which found that the majority of nurses were not trained in wound dressing practice. Overall wound dressing practice of nurses was at the level of a median score of practice and most of the nurses were within the medium level of practice; this result agrees with the results of Atiyah et al. $d$ that nurses had performed suboptimal wound dressing practices. This result disagrees with results of a study from Bangladesh, which mentioned that $85 \%$ of nurses used inappropriate dressing technique in caring for the surgical patient. $^{12}$ Regarding wound dressing practice steps the higher mean score was with applying irrigation and dressing and the lower mean score was with discard wound dressing supply this result supported by results of a study from Baghdad $^{2}$ that stated that adequate practice was with applying wound dressing and inadequate practice with care after dressing technique. Also, results of this

Table 4: Overall wound dressing practices levels among 64 nurses.

\begin{tabular}{lcc}
\hline Overall wound dressing practice levels & F & $\%$ \\
\hline Medium & 42 & 65.6 \\
High & 22 & 34.4 \\
Total & 64 & 100 \\
\hline
\end{tabular}


study agree with the results of another study from Baghdad, ${ }^{6}$ which found that wound preparation and discard supplies with documentation were a low mean score of practice. Regarding preparation and assessment steps of the wound dressing, study sample had a low grand mean score with low practiced especially items related to infection control practice like preparation sterile field with equipment, hand washing and wearing sterile gloves. This result may be related to the lack of training or workshop about infection control practice and policy of the hospitals relating improving quality of their care. This result disagrees with results of two studies from Brazil ${ }^{15,16}$ and guideline ${ }^{17}$ that verified that negligence, luck or deficit hand washing before and after wound dressing, exposing the patient to the pathogen and hospital infection risks. The sterile technique will be used in acute care setting; wearing sterile gloves allow handling of sterile supplies without contamination and open sterile dressing tray, or individually wrapped sterile supplies place on the bedside table. This result agrees with the results of a study from Bangladesh ${ }^{12}$ and Baghdad ${ }^{6}$ that found that nurses practice were with low mean score regarding wound dressing preparation and applying sterile technique and infection control practices. The results showed that there were no significant relationships between wound dressing practices and nurses age, although the old nurses were slightly better practiced than younger. This result may be related to the older nurses had more experience than younger nurses this result along with the result of a study from the Philippines, which stated age observed was not determinants of the practice on the principles of sterile technique. ${ }^{18}$ The finding of this study shows that there was no significant relationship between wound dressing practices with nurse's gender. This may be related to the majority $(82.8 \%)$ of both genders having the same level diploma in nursing. This result disagrees with results of a study from Baghdad, which found that male nurses were dominant since about $29.0 \%$ of them were categorized under high practice level of wound dressing practice while $0 \%$ of female nurses. ${ }^{2}$ The current study found that the more years of education, the better wound dressing practice at nonsignificant level. This may be due to the majority of nurses were in the same level having a diploma in nursing this result agree with the results of a study from Baghdad, which found that nurses with bachelor degree showed high practice level comparing with other nurses' educational backgrounds. ${ }^{2}$ In this study, the results show that the year of experience was not a significant factor affecting the wound dressing practice this may relate to the fact that the less year of experience those that had the higher level of nursing education and most of the nurses having less than five years of experience. This result disagrees with the results of a study from Ludhiana that found the nurses who have more years of experience are more skillful in wound dressing practices although the more years of experience, the better practiced..$^{19}$ In this study results show that nurses who were trained had the same level of wound dressing practice with those nurses who were not trained. This may be related to negligent of nurses within professional activities, and poor monitoring policy of the hospitals for improving quality of care. This result supported by the results of a study from Baghdad, which found that the nurses who had participated in training sessions performed the same practices of others. ${ }^{2}$ There were significant associations between the wound dressing practice and hospitals setting, nurses' who worked in Emergency Management Center had better practiced wound dressing than other hospitals. This may be related to the policy of the hospital that provides a qualified nurse for the hospital from the beginning of the when constructed hospital till now.

\section{Conclusion}

In this study, the overall nurses' wound dressing practice was sub optimal and the 
lowest practice was with items related to wound dressing infection control practice and items that related to discarding wound dressing supplies. The study recommends that standards infection control should be practiced by nurses and developing their skills during opening special training session concerning wound dressing and standards infection control in emergency wards.

\section{Competing interests}

The authors declare that they have no competing interests.

\section{References}

1. Tissue Viability Specialists (TVS). Clinical Protocol for Wound Management and Wound Management Standards: Clinical Policies and Procedures Group; 2013. Accessed Aug 12, 2015 at: http://www.wirralct.nhs.uk.

2. Atiyah $\mathrm{H}$, Khudhur $\mathrm{KH}$, Hasan S. Evaluation of nurses' practices toward postoperative wound dressing in surgical wards. Iraq Natl J Nursing Specialties 2012; 25(1):29-39.

3. Perry A,Pottor P,OstendorfW.Clinical nursing skills and techniques. $8^{\text {th }}$ ed.St. Louis; Mosby;2014. Accessed Oct 16, 2014 athttp://www.elsever.com.

4. Steror A, lindauer C, Proehl J, Barnason S, Brim $C$, Crowley $M$, et al.Clinical practice guideline. Wound preparation full version. Emergency Nurses Association; 2011. Accessed Sep 14, 2014 at: http://www.ena.org/practiceresearch.

5. Matias E. First Aid Management of Skin Injuries; First Aid Re-Certifications; 2014.Accessed Jun28, 2014 at: http://firstaidrecert.com.

6. Bader R,Kadhim Y. Evaluation of nurses' practices toward orthopedic wound infection. Iraq Natl J Nursing Specialties 2012; 25 S:58-70.

7. Australian Wound Management Association .Pan Pacific Clinical Practice Guideline for the Prevention and Management of Pressure Injury, Abridged Version, AWMA; Cambridge Publishing, Osborne Park 2012 (27).

8. Sardina D. Is your wound cleansing Practice up to date; Best practices. Wound Care Advisor 2013 (2):3.

9. Pamela L. Taylor. Clinical nursing skills, 3rd edition, Wolters Kluwer, Lippincott Williams and Wilkins, Philadelphia; 2012. P. 60-6.

10. Word health organization (WHO). Practical Guidelines for Infection Control in Health Care Facilities; New Delhi: SEARO Regional Publication No. 41 WPRO Regional Publication. 2004

11. Ben Saoud I, Elsour I, Elbargathi A, Elmarak A, Ali E. Knowledge Attitudes and Practices of Health Care Workers in Benghazi, Libya towards
Post Exposure Prophylaxis for HIV.Ibnosina J Med BS 2013; 5(6):318-23.

12. Sickder H. Nurse's knowledge and practice regarding prevention of surgical site infection in Bangladesh, MSc. Thesis. SongklaUniversity, College of Nursing. Bangladesh; 2010. available at: http://kb.psu.ac.th.

13. Kizzal B, Muliira JK. Nurses' knowledge and practices related to pain assessment in critically ill adultpatients.International Nursing Review. International Council of Nurses. Research Gate; 2015. Available at: https://www. researchgate.net.

14. Famakinwa T, Bello B, Oyeniran Y, Okhiah O, Nwadike R. Knowledge and practice of postoperative wound infection prevention among nurses in the surgical unit of a teaching hospital in Nigeria. International Journal of Basic, Applied and Innovative Research IJBAIR 2014, 3(1):23-8.

15. Perry AG, Potter PA, Ostendorf W. Clinical Nursing Skills and Techniques8: Clinical Nursing Skills and Techniques. Elsevier Health Sciences 2006:1264.

16. Nonino EA, Anselmi ML, Dalmas JC. Quality assessment of the wound dressing procedure in patients at a university hospital. Rev Lat Am Enfermagem 2008; 16(1):57-63.

17. Saskatoon health region. Wound irrigation and packing, Policies and Procedures, Saskatoon City Hospital Royal University Hospital, nursing, 2013. Accessed July 3, 2015 at: https://www.saskatoonhealthregion.ca.

18. Labrague LJ, Arteche DL, Yboa BC, Pacolor NF. Operating Room Nurses' Knowledge and Practice of Sterile Technique. J Nurs Care 2012; 1:4.

19. John M. Wound dressing practices, Nurs India J 2002; (93):8. 